\title{
Manipulative Use of Short Messaging Service (SMS) Text Messages by Nigerian Telecommunications Companies
}

\author{
Kehinde A. Ayoola (Ile-Ife)
}

\begin{abstract}
This paper is an application of Relevance Theory for the interpretation of short messaging service (SMS) text messages emanating from Nigerian telecommunications companies to their subscribers. The aim of the research was to identify and describe the manipulative strategies employed by Nigerian telecommunications companies to induce subscribers to part with their money through sales promotion lotteries. 100 SMS texts were purposively extracted from the cell phones of randomly selected residents of Lagos Nigeria who had received promotional SMS text messages from three major Nigerian telecommunications companies. Using Sperber and Wilson's Relevance Theory (1995) as its theoretical framework, the paper described the manipulative use of SMS by Nigerian telecommunications companies. The analysis revealed that SMS text messages were encoded to achieve maximization of relevance through explicature and implicature; contextual implication and strengthening; and the reduction of processing effort through violating the maxim of truthfulness and the creative use of graphology. The paper concludes that SMS text-messages were used manipulatively by Nigerian telecommunications companies to earn indirect income from sales promotion lottery.
\end{abstract}

\section{$1 \quad$ Introduction}

Advance in science and technology in the last two decades, particularly micro-chip-dependent technology such as computers, lasers, the Internet, satellite, videophones, etc., have helped in advancing the frontiers of global communication. The GSM (global system for mobile communication) revolution began in Nigeria in August 2001 and changed the face of information and communication technology in the country. Within a year of the introduction of GSM in the country, subscribers exceeded a million, making the possession of mobile phone no longer the exclusive preserve of the affluent minority. Today, Nigerian mobile telephone subscription exceeds 60 millions. Taiwo (2012: 64-83) observed that SMS is used widely in Nigeria for identity formation, romance, business, and several other socio-cultural purposes. He also identified its many negative uses by Nigerians which include perpetration of fraud, fuelling of ethnic crises, and examination malpractices, among other mischievous uses (cf. id.: 112-122).

SMS, the acronym for short message service, is the text communication service component of phone, web or mobile communication systems, using standardized communication protocols that allow the exchange of short text messages between fixed line or mobile phone devices. According to Taiwo (id. :9), it is designed to allow the exchange of short text messages between users of mobile phones. It is a standard and inexpensive service provided by modern 
telecommunications companies to ease interpersonal communication. Consequently, cell phone users can communicate with one another using symbols and/or abbreviated forms of word and sentence to save space, time and money. Very much like the telegram, the essence of the SMS is to be able to send and receive messages among cell phones users, in short forms, without losing relevance and clarity.

Since text messages are generally limited to 160 characters, users have devised means of maximizing the space by the frequent use of minor sentences, condensed expressions, letter/number homophones and non-conventional spellings. Thurlow (2003) observes that young people are the driving force behind a text messaging culture. Text messaging, according to Reid and Reid (2004), helps its users to develop, establish and maintain social contacts. The social ecology of text messaging shows that close knit groups of text mates are emerging, forming text-circles within which SMS texts are regularly exchanged. The broad categories of linguistic forms emerging from text message use are identified by Thurlow (2003) as: (a) Shortening (b) non-conventional spellings (c) acronyms and initialism (d) letter/number homophones (e) misspelling and (f) accent stylization.

Awonusi (2002: 47) observes that the fact that SMS readers contend with features such as send, reply, delete, forward, save, etc. in their handsets shows that "response strategies exist to make discourse structure bi-directional if the decoder chooses to give a feedback". Aside from using SMS to give subscribers updates on their account status and give routine information, one could deduce that Nigerian telecommunications companies use the medium to enhance their companies' balance sheets through SMS-based promotions. These promotions take several forms, viz.: awareness about new products and services; information on opportunities for bonuses and price reduction for loyal subscribers; and lastly, initiating promotions that have the characteristics of gaming or lottery.

The competitive business climate prompted Nigerian telecommunications companies to try various means at their disposal to get potential customers to subscribe to products or services on offer. Each service provider wants potential customers to consider its product or service to the exclusion of other similar products or services offered by rival telecommunications companies. Consequently, they use SMS to circulate advertisements aimed at securing the continued patronage of their subscribers. The underlying hypothesis of this paper was that Nigerian telecommunications companies went beyond merely encouraging the loyalty or patronage of their subscribers; but that they used subtle underhand tactics to enhance their income through self-serving promotions. The aim of this study was to identify and describe the manipulative strategies employed by Nigerian telecommunications companies to induce subscribers to part with their money through sales promotions that have the semblance of lottery. 100 SMS texts were purposively extracted from the cell phones of randomly selected residents of Lagos Nigeria who had received promotional SMS texts from three Nigerian telecommunications companies. Using Sperber and Wilson's Relevance Theory, the paper describes the manipulative use of SMS by Nigerian telecommunications companies. 


\section{Manipulation as a Cognitive Phenomenon}

Manipulative Discourse attempts to explore the interplay of ideas or motives between a manipulator and the minds of those he or she intends to manipulate. Manipulation is viewed as a communicative and interactional practice, in which a manipulator exercises control over other people, usually against their will or against their best interests. In other words, manipulators make others believe or do things that are in the interest of the manipulator, and against the best interest of the manipulated. One of the characteristics of manipulation according to van Dijk (2006: 361) is that it involves control, and that this control is first of all a control of the mind and indirectly a control of the actions of the recipients based on such manipulated beliefs. According to van Dijk (id.: 362), manipulation can be analysed at the macro level of analysis exemplified by "group membership, institutional position, profession, material or symbolic resources and other factors that define the power of groups and their members." Consequently, because of their institutional position, knowledge or profession, parents manipulate children, professors manipulate students, politicians manipulate voters, journalists manipulate recipients of media discourse, and religious leaders manipulate their followers (cf. Ayoola 2011). It is also possible to have institutional manipulation which takes the form of text or talk and it often entails access to the mass media or some form of public discourse exemplified by opinion articles, pamphlets, TV talk shows, advertisements, Internet blogs, and so on.

According to Rigotti (2005: 68), in manipulation, "what is negative has to be somehow disguised as something positive", and that manipulation "twists the vision of the world [...] in the mind of the addressee." Manipulative discourse is typically carried out in public communication dominated by bureaucratic, media or corporate entities. Manipulation is a form of power abuse often employed in media discourse to make a reader succumb to a position that basically promotes the interest of the manipulator above his/her own best interest. Manipulation, according to van Dijk (2006: 361, emphasis added), involves a form of mental manipulation which he describes as

a social phenomenon - especially because it involves interaction and power abuse between groups and social actors - a cognitive phenomenon because manipulation always implies the manipulation of the minds of participants, and a discursive phenomenon because manipulation is being exercised through text, talk and visual messages.

He further asserts that "Manipulation is one of the discursive social practices of dominant groups geared towards the reproduction of their power." Such dominant groups may do so in many other ways as well, e.g. through persuasion, providing information, education, instruction and other social practices that are aimed at influencing the knowledge, beliefs and (indirectly) the actions of the recipients. He avers that manipulation not only involves power, but specifically abuse of power, that is, domination. More specifically, it implies the exercise of a form of illegitimate influence by means of discourse.

Maillat and Oswald (2009) identify some criteria for characterizing manipulation, viz.: truthconditionality violation, speaker interest, covertness, social inequality and intention. According to them, manipulation is "a form of communication that puts the addressee in a situation where s/he will be led to shallow-process contextual assumptions" (id.: 362). They view manipulation as "essentially a cognitive process, which successfully misleads context 
selection" (id.: 363). They however disagree with van Dijk's proposition by arguing that manipulation is not necessarily negative, neither is it always in the best interest of the manipulator. For instance, when a patient is being cajoled to undergo a painful but beneficial treatment course or the complete truth about Santa Claus is not revealed to a child, then manipulation serves a positive purpose because it is done to the advantage of the one being manipulated. According to them, "speaker and hearer interests converge" (ibd.) because the child grows up to be a better citizen and the patient lives to become useful to himself or herself and the community at large. Maillat and Oswald went further to establish that social asymmetry is not a necessary condition for manipulation of the weak by the strong. They argue convincingly that it is equally common for a weak discourse participant to effectively manipulate a stronger or dominant party. It is also commonplace for people on the same level to manipulate one another. This argument wipes out the unspoken hypothesis that manipulation is unidirectional; whereby the weak always suffer at the hands of the strong.

Generally speaking, manipulation has negative associations such as domination, abuse of power, illegitimate influence, exploitation, and oppression because the practice violates social norms. Van Dijk (2006: 363-364) describes it as "illegitimate in a democratic society because it (re)produces inequality; it is in the best interest of powerful groups and speakers, and hurts the interests of less powerful groups and speakers." Manipulation should be distinguished from persuasion because in persuasion, participants or recipients of a message are free to believe or act as they please, depending on whether they accept the opinion of the speaker or writer. However, in manipulation, recipients typically assume a passive role in that the manipulated is usually at the mercy of the manipulator. According to van Dijk (id.: 365),

Discourse in general, and manipulative discourse in particular, involve processing information in short term memory (STM), basically resulting in 'understanding' (of words, clauses, sentences, utterances and non-verbal signals) for instance in terms of propositional 'meanings' or 'actions'.

One form of manipulation consists of controlling some of this partly automatized strategy of discourse understanding. For example, by printing part of a text in a salient position and in upper cases and bolder fonts; these tools will attract more attention and as a result, will be processed with extra time or memory resources.

It is also worthy of note that discourse structures are not manipulative; they only have such functions or effects in specific communicative situations and the way in which these are interpreted by participants in their context models. This implies that a discourse structure may be manipulative in one situation, but not necessarily so in another situation. Kintsch (1998) and van Oostendorp and Goldman (1999) among others demonstrated that understanding can be influenced by various contextual and textual manipulations. Manipulative discourse has attracted a lot of attention in various adjacent domains of linguistic research, notable in rhetoric, argumentation theory, philosophy of language, discourse analysis, pragmatics, among others. Manipulation systematically exploits the inherent weakness or flaws of the human cognitive system that are aptly discussed in cognitive psychology under the heading Cognitive Illusions. 


\section{$3 \quad$ Relevance as a Potential Property of Utterances}

Relevance theory, often associated with Sperber and Wilson (1995, 1998, 2002a), has been developed in the last two decades in several publications (see also Wilson/Sperber 2012 and Sperber 2005). The theory is built on Grice's (1989) central claims that an essential feature of human communication is the expression and recognition of the communicator's intentions. The main argument of relevance theory is that the human cognitive system has developed a variety of dedicated mental mechanisms or biases which tend to allocate attention to inputs with the greatest expected relevance, and processes them in the most relevance-enhancing way (cf. Sperber/Wilson 1995). The theory further builds on Grice's central claim that utterances automatically create expectations which guide the hearer towards the speaker's meaning, which has been summarized as the co-operative principle and the four maxims: quality, quantity, relation and manner (cf. Grice 1989). According to relevance theory, the expectations of relevance raised by an utterance are precise and predictable enough to guide the hearer towards inferring the speaker's meaning. Consequently, relevance should be viewed not only as a potential property of utterances and other observable phenomena, but of thoughts, memories and conclusions of inferences.

Relevance theory is basically an inferential theory of communication, which aims to explain how the audience infers the communicator's intended meaning inherent in an utterance. According to Sperber and Wilson (1998), a verbal utterance is a stimulus that the addressee uses as evidence to infer the speaker's meaning in an appropriate context. To them, communication involves the production of an ostensive stimulus from which the audience draws an inference after some processing effort. They argue that ostensive-inferential communication exploits a general cognitive principle: that the mind tends to attend primarily to information which is relevant to it, in a technical sense (cf. Sperber/Wilson 1995). The basic point about ostensive-inferential communication is that the communicator intentionally provides evidence that he intends the audience to arrive at certain conclusions.

Relevance theory distinguishes between the speaker's informative intention and his or her communicative intention. According to Sperber and Wilson (id.: 260), human cognition "tends to be geared to the maximization of relevance"; hence the human cognitive systems associate ease or difficulty in processing a piece of information with the optimal benefit the recipient seeks to derive from it. Since the mind tends to allocate its resources to the most relevant information, if a communicator wishes to be understood, he or she is expected to produce a stimulus which is at least relevant enough to the addressee to be worth attending to. The addressee can therefore interpret the stimulus on the assumption that it will be adequately relevant to him or her.

Relevance theory distinguishes between the proposition expressed and the proposition that is explicitly communicated by the utterance in terms of its explicature and implicature. According to relevance theory, the explicature of the utterance, like its implicature, may be strongly or weakly communicated. While explicature refers to the logical form encoded by the utterance; implicature encapsulates the inferences drawn from the utterance; hence the explicit meaning of an utterance logically warrants the implicated conclusions. In Sperber and Wilson's (1995) terms, an utterance produces positive cognitive effects, which are of three 
main types: contextual implication, contextual strengthening, and contextual contradiction and elimination.

\section{Applying Relevance Theory to the Interpretation of SMS Texts}

According to relevance theorists, an ostensive stimulus is optimally relevant to an audience if it is relevant enough to be worth the audience's processing effort and if it is compatible with the communicator's abilities and preferences (cf. Sperber/Wilson 2002b: 257). This paper is concerned with the interpretation and explanation of promotional SMSes emanating from Nigerian telecommunications companies to subscribers nationwide. Relevance theory was applied to the SMS texts for a scientific description of the telecommunications companies' informative intention and elicitation of their communicative intention. This enabled us to arrive at an informed and objective generalization on corporate abuses of the SMS in Nigerian socioeconomic situation.

The analysis of the data was undertaken under four subheadings: expectation of optimal relevance from Nigerian telecommunications subscribers; maximising relevance through explicatures and implicatures; violating the maxim of truthfulness; and reducing processing effort through manipulative use of punctuation and capitalization.

\subsection{The Expectation of Optimal Relevance from Nigerian Telecommunications Subscribers}

Nigeria plays host to a few transnational companies, prominent among which are oil corporations and telecommunications companies that are widely believed to earn stupendous income from an economy whose burden is tilted precariously against the ordinary citizen. As a way of addressing this lopsidedness, Nigerian multinational companies are mandated by law to have corporate social responsibility (CSR) units in their establishments. These units are expected to partner with the government in a superficial bid to help reduce poverty and contribute to the growth of the economy through investment in projects that benefit the average Nigerian. Consequently, frontline Nigerian telecommunications companies, exemplified by the trio of AIRTEL, GLOBACOM and MTN are reputed to have spent millions of dollars annually on football sponsorships, award of scholarships to tertiary institution students, renovation of public facilities and many more in the last decade. These charitable deeds are so publicized on both the electronic and non-electronic media that the ordinary Nigerian is bound to have formed the opinion that the companies are not only stupendously rich, but are desperate to spread their wealth to as many ordinary Nigerians as possible. This is the spacio-temporal context of the SMS texts sent to Nigerian telecommunications subscribers from their telecommunications service providers. The following are some examples:

TEXT A

Congrats! You dey among lucky people for XXXX's N1 million today. It's easy. Simply text WIN to 777 and you can also win N10 million this month and N30 million! Costs N100/SMS. 


\section{TEXT B}

If your number ends in $4, \mathrm{XXXX}$ chose you today 25/07 to participate for N24,000,000! Send XXXX to 2012 and activate your participation! N100/SMS.

\section{TEXT C}

Once beaten, twice shy! Na serious wahala if you miss another opportunity to play for tonight's N1 million from XXXX! Let's go: text WIN to 777! Costs N100/SMS.

The communicative principle of relevance stipulates that every act of ostensive communication communicates a presumption of its own optimal relevance which is (a) the ostensive stimulus is relevant enough to be worth the receiver's effort to process it and (b) the ostensive stimulus is the most relevant one compatible with the communicator's abilities and preferences (Sperber/Wilson 1995: 270). Texts A - C above, which emanate from Nigerian telecommunications companies, are examples of SMS text messages received by Nigerian telecommunications subscribers from their telecommunications service providers. As the receiver reads the message, his or her mind is befuddled with "flashbulb memories" of donations to sports and other worthy causes like sponsoring disabled students' education by the communicator.

Consequently, the scenario of "cash splash" by Nigerian telecommunication companies strengthens the relevance of SMS text messages emanating from them. This contextual implication is expected to trigger an expectation of optimal relevance in the SMS text message recipient that the telecommunications company, which has proven to be a friend of the underclass through its charitable deeds, is out again to improve the lot of ordinary Nigerians. It is immaterial to the recipient that the message had also been sent to millions of other subscribers; what matters to him or her is that for as little as N100 (about 65 cents), he or she could become a millionaire! This expectation of optimal benefit on the part of the SMS recipient is not out of place in the Nigerian socio-economic environment where the minds of ordinary citizens have previously been flooded with media reports and advertisements about the good deeds of the communicator.

We have already established in our literature review that manipulation is an attempt at misleading the addressee which ensures that only a limited set of contextual assumptions is accessed by taking advantage of her/his cognitive optimism. The informative intention of the communicator in Texts $\mathrm{A}-\mathrm{C}$ is that the telecommunications company is spilling out millions of naira (Nigeria's currency) to interested subscribers; while their communicative intention is that all that the recipient needs to do to benefit from this windfall is to activate his or her participation with an amount as little as 65 cents. We must not fail to observe that majority of Nigerians live below the poverty line; hence they are more of dreamers than partakers of the country's stupendous oil wealth. The expectation of optimal relevance of becoming a millionaire or winning a new car by a mind already softened by hardship and deprivation is contextually strengthened in a country where people are reputed to become multi-millionaires after misappropriating public funds with impunity or engaging in other forms of underhand activities. Unknown to the recipient, a paltry investment of 65 cents by say ten million unsuspecting subscribers equals the princely sum of 6.5 million US Dollars! This whopping estimate points at the communicator's nested intention (cf. Grice 1989); hence the real reason for despatching the manipulative SMS to the telecommunications subscribers. 


\subsection{Maximizing Relevance through Explicature and Implicature}

The relevance-theoretic comprehension procedure states that a recipient follows the "path of least effort in computing cognitive effects" (Sperber/Wilson 1995: 58). He or she considers interpretations such as reference assignments, contextual assumptions, implications, etc. in order of accessibility and he or she stops when his or her expectations of relevance are satisfied (cf. Sperber/Wilson 1995). Implicatures are not blatantly encoded and yet they occur frequently in verbal communication. The reader draws predictable implicit premises and conclusions from the message. As a critical discourse analyst, one is inclined to evaluate an SMS text message as manipulative more because of the implicature of its contextual background than the explicature of its textual structures. This observation is illustrated with examples from the data:

\section{TEXT D}

Can you hear it? Tonight's N1 million cash from XXXX is calling you! Don't turn your back! Get a chance with just 1 SMS! Simply text WIN to 777! Costs N100/SMS.

TEXT E

LAST CALL for 0123456789 from XXXX! You haven't activated your

PARTICIPATION for N12,000,000 THIS SUNDAY. Send XXXX to 2012 or else it will be wasted. N100/SMS.

\section{TEXT F}

LAST CALL for 0123456789 from XXXX! Don't waste your free participation for TOYOTA YARIS! SEND FREE to 1212 \& go for the CASH \& TOYOTA YARIS!

Few hours left!

Text D can be described structurally as a dramatic monologue in which the SMS opens with an interrogative sentence closely followed by its answer in the form of a declarative sentence. This sequence is followed by three imperative sentences in a row urging the recipient to act in a manner that is potentially rewarding for the communicator, but remotely beneficial to the recipient. Analysing the text explicatively, the recipient is being urged to act wisely by responding positively to the communicator's kind offer to him or her. The implicature of Text D can be inferred as follows: The uncritical recipient is expected to believe that he or she is one of the few lucky subscribers who have been randomly selected by the telecommunications company to benefit from its good cause of turning ordinary Nigerian citizens into millionaires. A similar implicature can be derived from Texts $\mathrm{E}$ and $\mathrm{F}$ that the "selected" subscriber's wellbeing matters to the communicator; hence the close monitoring of his or her participation in a promotion that is ostensibly open to only a select few. Consequently, it will be foolhardiness on the part of a rational subscriber not to risk a mere 65 cents to "activate" his or her participation in this apparent windfall.

Relevance is further maximised in the texts through the use of Pidgin English (Texts A and C). Aside from triggering the feeling of camaraderie in the mind of the recipient, the use of Pidgin English has the potential of making the message more accessible to millions of Nigerians who might have been cut off by the use of Standard English in previously sent SMS text messages. There is also the personalization of the SMS through the use of personal pronouns and reference to the recipient's phone number (Texts E and F). The implicature of 
this is that the recipient is expected to infer that the message has been sent especially to him or her and it is not a general SMS to all subscribers. There is also the tantalising dangling of "one million naira cash" and a new "Toyota Yaris" car (Texts D and F) in the SMS text messages. This has the potential of opening the door to the recipient's imagination and prompting him or her to decide that staking 65 cents will not bankrupt him or her but that it could make him or her a millionaire or the owner of a Toyota Yaris car.

\subsection{Reducing Processing Effort by Violating the Maxim of Truthfulness}

Relevance theory postulates that each utterance raises an expectation of optimal relevance, but it does not claim that the presumption will always be true or that it will always be taken as true. The communicators of the SMS text messages employ several underhand tactics to win over their recipients. Such manipulative tactics, which violate the maxim of truthfulness, include the use of informal language, carrot dangling, deception and outright lies.

TEXT G

TOP SECRET: you dey among the people XXXX don select for this Thursday's N10 million draw! No tell anybody o! ... Just text WIN to 777 now! Costs N100/SMS.

TEXT H

Na you hold the key to tonight's N1 million cash and the 30 million from XXXX! Unlock your destiny by texting WIN to 777 now! Costs N100/SMS.

\section{TEXT I}

Shhh, dis one na secret... don't tell anyone! Your name is among XXXX's favourites for tonight's CASH! Grab it by texting WIN to 777 now! Costs N100/SMS.

The use of Pidgin English by the communicators is apparently advised by the hunting maxim: "if you wish to catch a monkey you have to behave like one". The manipulative use of Pidgin in Texts A, C, D, G, H, and I demonstrates that the ultimate target of the communicator is the poorly educated Nigerian underclass comprising artisans, market men and women, farmers, labourers, factory workers, unemployed people, etc. This use violates the maxim of truthfulness because the communicator is a false pretender. The SMS text message encoder has been described as such because he or she does not belong to the class of people or institutions that normally communicate in Pidgin English. He or she uses Pidgin English manipulatively to warm himself or herself into the heart of millions of Nigerian subscribers and consequently make them part with 65 cents after reading the text message.

A communicator can be described as violating the Gricean maxim of truthfulness when he or she says what he or she knows to be untrue. The following are some examples of deception and outright lies from the texts:

1. Congrats! You dey among lucky people for XXXX's N1 million today. (Text A)

2. TOP SECRET: you dey among the people XXXX don select for this Thursday's N10 million draw! (Text G)

3. Na you hold the key to tonight's N1 million cash (Text $\mathrm{H})$

4. Your name is among XXX's favourites ... (Text I) 
The maxim of truthfulness is violated when a communicator uses a vague expression, cracks an inappropriate joke or uses an aphorism inaccurately. Such usages found in the discourse are tagged manipulative because the exalted position occupied by the communicators in the Nigerian socio-economic context prohibits them from misleading the public. The choice of "congrats" in Example 1 raises a false hope in the recipient, while "TOP SECRET" in Example 2 is a platitude and an outright lie. That the recipient "holds the key" in Example 3 or that his or her name is on the list of "lucky people" violates the maxim of truthfulness because no ordinary Nigerian telephone subscriber is that important to a Nigerian telecommunications company. Since the recipient has an optimal expectation of truthfulness from a respected institution, it is relevant for him or her to assume that an SMS from his or her telecommunications company would be sincere and truthful.

The following are further examples of collocations that violate the maxim of truthfulness in the discourse:

1. Once beaten, twice shy! (Text C)

inaccurate aphorism

2. Let's go (Text C)

deceptive camaraderie

3. LAST CALL (Text E)

empty cliché

4. TOP SECRET (Text G)

empty cliché

5. Unlock your destiny ... (Text $\mathrm{H})$

deceptive camaraderie

Examples 6-9 above are further evidence of the violation of the maxim of truthfulness in the discourse and they have been tagged inaccurate aphorism, deceptive camaraderie and empty clichés, as appropriate. Such usages, which smirk of insincerity and manipulation on the part of the telecommunications companies, are unbecoming of respected corporate bodies.

\subsection{Reducing Processing Effort through Creative Use of Punctuation and Capitalization}

Punctuation and capitalization assist potential readers to more accurately interpret tonal features and added nuances of meaning such as focus, emphasis, contrast and contradiction in written texts. Consequently, a manipulative encoder uses them to great advantage by casting his or her message in a manner that reduces processing effort on the part of the decoder. This manipulative strategy is evident in the examples presented below:

TEXT J

GREAT NEWS from XXXX! TOYOTA YARIS? YES! Motorbike? Yes! N12,000,000 this SUNDAY? Yes! N24,000,000 at the end? Yes! FOR FREE? YES! Send FREE for FREE to 1212 NOW!

TEXT K

GREAT NEWS for LOYAL SUBSCRIBER XXXX! You are awarded with 250 EXTRA CHANCES for the N24,000,000! Answer the next question now to redeem them.

TEXT L

EXCLUSIVE OFFER FROM XXXX! EXTRA PRIZE: A MOTORBIKE! ONLY 
TODAY you can win up to N3,000,000 and a MOTORBIKE! Send 2 to 2012 now and go for the prizes!

In Text $\mathrm{J}$, the reader is enabled to perceive the use of rising and falling tones by a pushy and excitable sales person through the alternate use of exclamation and question marks in the text. These two punctuation marks, which give dialogic effect to the short minor sentences in the SMS text messages, are capable of achieving the manipulative effect of personal warmth or camaraderie on the part of the communicator on the one hand and the need for prompt urgent action on the part of the recipient on the other hand.

Likewise, capitalization has been used copiously in the SMS text messages to ease processing effort by drawing the receiver's attention to items of optimal benefit and important action points in the discourse. Lexical items and collocations that highlight optimal benefits can be exemplified with "TOYOTA YARIS", "LOYAL SUBSCRIBER" and "MOTORBIKE" in Text J, K and L, respectively. Capitalizing time adverbials "SUNDAY" and "NOW" in Text J eases the shallow processing of the texts to the effect that the recipients are prompted to take the easy step of merely entering the words WIN or FREE to activate their participation in the promotion. The manipulative use of punctuation and capitalization by agents of the telecommunications companies has the potential of producing the positive cognitive effect of contextual strengthening on the mind of the recipient, prompting him or her to take the decision of investing 65 cents towards becoming a millionaire or owning a brand new car.

\section{Concluding Remarks}

Does the operating licence granted Nigerian telecommunications companies by the Nigerian Communications Commission (NCC) permit gaming and other gambling activities? The answer to this question is negative. This is because such powers reside with the National Lottery Regulatory Commission. Notwithstanding, the main telecommunications companies in the country have engaged in gaming activities for over three years. On 8th November 2012, the NCC announced a ban on all promotions by telecommunications companies because the commission had been inundated with complaints from consumers and industry watchers against the various promotions offered by the companies.

Since the telecommunications companies were not licensed to engage in gambling or gaming activities, it was logical for members of the public to assume that the promotions were a manifestation of the companies' corporate social responsibility (CSR) to the Nigerian public. The mere fact that telecommunications subscribers were expected to experience a deduction of their call credit to activate their participation makes the promotional activities suspicious. If the companies were truly altruistic, subscribers wouldn't have suffered any deduction at all. The rules of the promotions were not sufficiently spelt out; the motives and the truth about the telecommunications companies' benefits from the promotions were not made public. While most subscribers were guaranteed to lose their stake, the GSM service providers were guaranteed to lose nothing since they have little or nothing at stake in the first place. They hold both the cake and the knife; there is no formal contract between them and the subscribers; hence they are not under any obligation to be fair to them. 
The analytical framework of Sperber and Wilson's Relevance Theory was applied to elicit the manipulative use of SMS text messages to boost Nigerian telecommunications companies' balance sheets at the expense of ordinary Nigerian telecommunications subscribers. The telecommunications companies presented their messages through the cheap and opportunistic medium of SMS in a manner that misrepresented them to the recipient as bountiful givers anxious to share their wealth with selected members of the Nigerian public. The socioeconomic context of the SMS text messages made it logical for the recipients to process the text messages as optimally relevant for them to expect to win fairly in a competition with other randomly selected members of the Nigerian public.

\section{References}

Awonusi, Victor O. (2002): "Little' English and the Law of Energetics: A Sociolinguistic Study of SMS Text Messages as Register and Discourse in Nigerian English". In: Adetugbo, Abiodun/Awonusi, Segun/Babalola, Emmanuel A. (eds.): The Domestication of English in Nigeria. Lagos, University of Lagos Press: 45-62.

Ayoola, Kehinde A. (2011): "Some Manipulative Dimensions of Newspaper Reporting of the Niger Delta Conflict in Nigeria". In: Alao, Akin/Taiwo, Rotini (eds): Perspectives on African Studies. Essays in Honour of Toyin Falola. Muenchen, Lincom Europa: 379-394.

Grice, Paul (1989): Studies in the Way of Words. Cambridge: Harvard University Press

Kintsch, Walter (1998): Comprehension: A Paradigm for Cognition. Cambridge: Cambridge University Press.

Maillat, Didier/Oswald, Steve (2009): "Defining Manipulative Discourse: The Pragmatics of Cognitive Illusions". International Review of Pragmatics 1: 348-370.

Reid, Donna/Reid, Fraser (2004): "Insights into the Social and Psychological Effects of SMS Text Messaging." http://www.160characters.org, accessed November 17, 2012.

Rigotti, Eddo (2005): "Towards a Typology of Manipulative Processes". In: Saussure, Louis de/Schulz, Peter (eds.): New Perspectives on Manipulative and Ideological Discourse in Pragmatics and Discourse Analysis. Discourse Approaches to Politics, Society and Culture. Amsterdam, John Benjamins: 61-83.

Sperber, Dan (2005): "Modularity and Relevance: How can a Massively Modular Mind be Flexible and Context-sensitive?" In: Carruthers, Peter/Laurence, Stephen/Stich, Stephen (eds.): The Innate Mind: Structures and Contents. Oxford, Oxford University Press: 53-68.

Sperber, Dan/Wilson, Deirdre (1995): Relevance Theory: Communication and Cognition. Oxford: Blackwell.

Sperber, Dan/Wilson, Deirdre (1998): "The Mapping between the Mental and the Public Lexicon". In: Carruthers, Peter/Boucher, Jill (eds.): Language and Thought: Interdisciplinary Themes. Cambridge, Cambridge University Press: 184-200.

Sperber, Dan/Wilson, Deirdre (2002a): "Pragmatics, Modularity and Mind-reading". Mind and Language 17/1-2: 3-23.

Sperber, Dan/Wilson, Deirdre (2002b): "Relevance Theory". In: Horn, Laurence/Ward, Gergory (eds.): Handbook of Pragmatics. Oxford, Blackwell: 607-655.

Taiwo, Rotimi (2012): Language and Mobile Telecommunication in Nigeria: SMS as a Digital Lingual-Cultural Expression. Ile-Ife: Obafemi Awolowo University Press.

Thurlow, Crispin (2003): "Generation Text? The Sociolinguistics of Young People's TextMessaging". Discourse Analysis Online. http://extra.shu.ac.uk/daol/articles/v1/n1/a3/thurlow2002003-paper.html, accessed September 18, 2012.

Van Dijk, Teun A. (2006): "Discourse and Manipulation". Discourse and Society 17/2: 359383. 
Van Oostendorp, Herre/Goldman, Susan R. (eds.) (1999): The Construction of Mental Representations during Reading. Mahwah: Erlbaum.

Wilson, Deirdre/Sperber, Dan (2012): Meaning and Relevance. Cambridge: Cambridge University Press. 